\title{
IMOBILIZAÇÃO DE LIPASE DE Aspergillus niger POR ADSORÇÃO
}

T.L.D. SOARES ${ }^{1}$, K.F.S. KELLY ${ }^{2}$, I.R. BARBOSA ${ }^{3}$, F.C.A. SOUSA ${ }^{1}$, E.F. SOUZA ${ }^{4}$, T.L. AZEVEDO $^{4}$, A.A. SANTOS ${ }^{4}$, L.M.F. GOTTSCHALK ${ }^{4}$, M.P. STEPHAN ${ }^{4}$, C.M. SILVA ${ }^{4}$, A.I.S. BRÍGIDA ${ }^{4}$.

\footnotetext{
${ }^{1}$ Centro Universitário Estadual da Zona Oeste

2 Universidade Federal do Rio de Janeiro

${ }^{3}$ Universidade Federal Rural do Rio de Janeiro

${ }^{4}$ Embrapa Agroindústria de Alimentos

E-mail para contato: ana.iraidy@embrapa.br
}

RESUMO - As lipases de Aspergillus niger vêm sendo investigadas quanto sua aplicação na obtenção de fenóis funcionais, síntese de ésteres aromáticos, produção de biodiesel entre outras. Desta forma, o objetivo deste trabalho foi avaliar o processo de imobilização de lipase de $A$. niger $\mathrm{C}$ por adsorção em dois diferentes suportes: fibra de coco e octil-agarose. A adsorção ocorreu em banho finito, $\mathrm{pH}$ 7. Inicialmente foi avaliado o efeito da força iônica no processo de imobilização utilizando-se tampão fosfato de sódio $\mathrm{pH} 7$ de 5 e 50 $\mathrm{mM}$. Posteriormente, com o suporte selecionado, avaliou-se o efeito do tempo de contato tanto na atividade hidrolítica do derivado quanto nos valores de rendimento e atividade recuperada. O uso de baixa força iônica mostrou-se mais eficiente tanto em suporte heterogêneo (fibra de coco) quanto em suporte homogêneo (octil-agarose). A carga máxima de proteína imobilizada foi de $6,1 \mathrm{mg} / \mathrm{g}$ de octil-agarose. Além disso, o octil-agarose foi o suporte que apresentou maior atividade lipolítica $\left(3,2 \mathrm{U}_{\mathrm{AO}} / \mathrm{g}\right) \mathrm{em} 1$ hora de contato sendo, inclusive, este o período que promoveu atividade específica máxima $\left(0,13 \quad \mathrm{U}_{\mathrm{pNFB}} / \mathrm{mg}\right.$ de proteína).

\section{INTRODUÇÃO}

Os processos industriais que envolvem reações químicas estão presentes em grande parte das manufaturas de produtos ou bens consumidos pelo homem. Apesar dessas reações utilizarem catalisadores químicos, estes estão sendo substituídos por enzimas. As enzimas são proteínas especializadas em catalisar reações biológicas que aceleram a velocidade de uma reação. Estas podem ser obtidas de fontes vegetais, animais e microbianas. Os processos catalisados por enzimas comumente são mais eficientes e sustentáveis para o meio ambiente (Monteiro e Silva, 2009).

Dentre as enzimas, a maior classe e de maior aplicação industrial são as hidrolíticas, representadas por amilases, celulases, pectinases e lipases. As lipases são capazes de catalisar a hidrólise e a síntese de ésteres formados por glicerol e longas cadeias de ácidos graxos (Jaeger e Reetz, 1998), sendo as de uso comercial obtidas principalmente de microorganismos por meio de fermentação submersa ou em estado sólido. Industrialmente, as lipases são utilizadas na produção de têxtil, detergentes, alimentos, óleos e gorduras (Sharma et al., 2001). 
Muitas das espécies de Aspergillus são utilizadas para a obtenção de enzimas, na biossíntese química e na transformação de compostos. Aspergillus niger, por exemplo, vem sendo descrito como um produtor de várias lipases e esterases (Contesini et al., 2010).

Estudos de imobilização de enzimas têm sido desenvolvidos visando à implantação de processos contínuos, maior pureza do produto obtido, além da obtenção de catalisadores operacional e termicamente mais estáveis, (Blanco et al., 2004). Por apresentar poucos efeitos prejudiciais para a atividade e seletividade da enzima, além do baixo custo, o método de imobilização por adsorção é o mais comum. Dentre os suportes utilizados para a imobilização de lipases por adsorção tem-se octil-agarose, sílica, DEAE-agarose e celite (Villeneuve et al., 2000). Octil-agarose é um suporte comercial que, devido suas características hidrofóbicas, tem sido bastante utilizado nos estudos de imobilização como única etapa de purificação de lipases. Estudos realizados por Fernández-Lorente et al. (2005) tem mostrado eficiência na aplicação deste suporte para imobilização de lipase de A. niger. Em paralelo, visando contribuir para a redução dos custos de biocatalisadores imobilizados, o uso de suportes de baixo custo tem sido investigado. Dentre os suportes de baixo custo, a fibra de coco tem mostrado potencial como suporte para imobilização de lipase (Brígida et al., 2008). Contudo, devido a sua superfície heterogenia, o uso desse tipo de suporte para estudos de imobilização como única etapa de purificação deve ser cuidadosamente analisado. Desta forma, visando contribuir para o desenvolvimento de biocatalisadores estáveis, o objetivo deste trabalho foi avaliar o processo de imobilização de lipases de A. niger $\mathrm{C}$ por adsorção em dois diferentes suportes: fibra de coco verde e octil-agarose.

\section{MATERIAIS E MÉTODOS}

\subsection{Materiais}

Extrato rico em lipase de Aspergillus niger $\mathrm{C}$ foi obtido por fermentação em estado sólido conforme metodologia descrita por Gomes (1995). As fibras de coco verde foram fornecidas pela Embrapa Agroindústria Tropical, CE e lavadas com água conforme metodologia descrita por Brígida et al. (2008). O octil-agarose (CL 4B), o p-nitro fenil butirato e o dimetilsulfóxido foram adquiridos da Sigma-Aldrich Chemical Co.

\subsection{Métodos}

Imobilização da enzima: foi utilizado o extrato enzimático diluído em tampão fosfato pH 7. A proporção suporte:enzima foi de $1 \mathrm{~g}$ de suporte (fibra de coco) para $10 \mathrm{~mL}$ de extrato enzimático e de $0,3 \mathrm{~g}$ de suporte (octil-agarose) para $10 \mathrm{~mL}$ de extrato enzimático. A imobilização por adsorção ocorreu à $25^{\circ} \mathrm{C}$, sob agitação branda $(\sim 10 \mathrm{rpm})$, utilizando a técnica de banho finito. Após um dado tempo de contato, o sobrenadante foi separado do derivado por filtração e atividade de ambos foi determinada. Durante os estudos de imobilização, além de acompanhar a atividade hidrolítica no derivado obtido e do sobrenadante, o cálculo de dois outros parâmetros (atividade recuperada e rendimento de imobilização) foi fundamental para avaliar o desempenho do processo de imobilização. $O$ rendimento de imobilização $(\mathrm{R})$ pode ser definido como a quantidade de enzima teoricamente

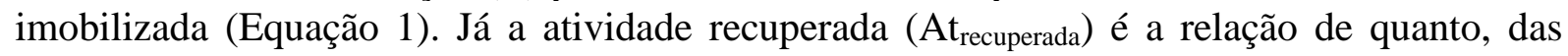


enzimas teoricamente imobilizadas, que se encontram ativas (Equação 2). A avaliação desses parâmetros indicaram as melhores condições de imobilização obtidas através deste estudo.

$$
\begin{aligned}
& R(\%)=\left(1-\frac{A t_{s}}{A t_{b}}\right) * 100 \\
& A t_{\text {recuperada }}=\frac{A t_{d}}{\frac{A t_{0}}{M s} * R} * 100
\end{aligned}
$$

sendo,

Ats: atividade hidrolítica medida no sobrenadante após um dado período de imobilização (U);

At $\mathrm{b}$ : atividade hidrolítica medida numa solução "branco" de mesma concentração inicial que a solução destinada a imobilização após o mesmo período destinado a $\mathrm{At}_{\mathrm{s}}(\mathrm{U})$;

$\mathrm{At}_{\mathrm{d}}:$ atividade hidrolítica medida no derivado $(\mathrm{U} / \mathrm{g})$;

$\mathrm{At}_{0}$ : atividade hidrolítica na solução inicial de enzima (U);

Ms: massa do derivado (g).

Efeito da força iônica: para avaliar o efeito da força iônica no processo de imobilização, foi utilizado o extrato enzimático diluído em tampão fosfato $\mathrm{pH} 7$ a 5 ou $50 \mathrm{mM}$. O tempo de contato foi mantido constante e igual a 1 hora.

Efeito do tempo de contato: amostras de sobrenadante e derivado do sistema de imobilização foram coletadas em tempos pré-definidos. Foi utilizado o extrato enzimático diluído em tampão fosfato pH 7 e a concentração do tampão foi selecionado de acordo com os estudos do efeito da força iônica.

Dosagem de atividade hidrolítica em azeite de oliva: Em banho-maria, à temperatura de $35^{\circ} \mathrm{C}$, sob agitação, colocou-se sistemas reacionais contendo azeite de oliva, tampão citrato e emulsão de goma arábica. A cada sistema adicionou-se $1 \mathrm{~mL}$, quando a amostra era o sobrenadante, ou 0,3 g, quando a amostra era o derivado. Após 15 minutos de reação, adicionou-se reagente de parada (acetona, álcool etílico e água na proporção 1:1:1) em todos os sistemas. Em seguida titulou-se com hidróxido de sódio $\mathrm{N}=0,0498 \mathrm{~N}$ (Gottschalk et al., 2012). Para esta metodologia, uma unidade $\left(\mathrm{U}_{\mathrm{AO}}\right)$ de atividade enzimática hidrolítica foi definida como a quantidade de enzima que libera $1 \mu \mathrm{mol}$ de ácido graxo por minuto nas condições propostas.

Dosagem de atividade hidrolítica em p-nitrofenil butirato: Acompanhou-se a hidrólise de p-nitro fenil butirato $(560 \mu \mathrm{M})$ via espectrofotômetro $(\lambda=410 \mathrm{~nm})$ durante 4 minutos. A reação ocorreu em temperatura ambiente $\left(25^{\circ} \mathrm{C}\right)$, em sistema agitado (placa IKA, $480 \mathrm{rpm}$ ) e tamponado utilizando tampão fosfato de sódio a $50 \mathrm{mM}, \mathrm{pH} 7$. O volume reacional foi de 20 $\mathrm{mL}$, no qual foram adicionados $150 \mu \mathrm{L}$ de solução enzimática. Para esta metodologia, uma unidade $\left(\mathrm{U}_{\mathrm{pNFB}}\right)$ de atividade enzimática hidrolítica foi definida como a quantidade de enzima que libera $1 \mu \mathrm{mol}$ de p-nitrofenol por minuto nas condições propostas. 
Dosagem de proteínas: A quantificação de proteínas na solução de enzima oferecida para imobilização e no sobrenadante final foi realizada pelo método de Bradford (1976). Com base nos valores obtidos, o teor de proteína imobilizada foi calculado.

Análise de eletroforese: Amostras contendo quantidades conhecidas de proteína foram adicionadas a igual volume de tampão de amostra (Tris-HCl 2 mol.L-1 pH 6,8, EDTA 0,2 $\mathrm{mol} / \mathrm{L}$, glicerol $10 \%$ e azul de bromofenol $0,5 \%$ ), fervidas por dois minutos, centrifugadas rapidamente e aplicadas em géis de $12 \%$ de SDS-poliacrilamida. Após a corrida, os géis foram corados com Coomassie de acordo com protocolos descrito na literatura (LAEMMLI, 1970). Marcadores de baixo peso molecular foram utilizados como padrão.

\section{RESULTADOS}

\subsection{Efeito da força iônica no processo de imobilização por adsorção}

Imobilização em fibra de coco: Avaliou-se o efeito da força iônica na imobilização de lipase de A. niger $\mathrm{C}$ em fibra de coco por adsorção no tempo de contato de 1 hora (Tabela 1$)$. $\mathrm{O}$ uso da baixa força iônica mostrou-se mais eficiente no uso do suporte heterogêneo (fibra de coco), onde foi obtida maior atividade no derivado e também maior quantidade de proteína imobilizada. O perfil proteico do sobrenadante e do imobilizado também foi avaliado por eletroforese (Figura 1). Em $50 \mathrm{mM}$ não foi possível visualizar qualquer banda de proteína no suporte, já em 5 mM percebeu-se leve banda entre 72 e 47 kDa.

Tabela 1 - Imobilização de lipases de A. niger C por adsorção em fibra de coco, utilizando tampão fosfato de sódio $\mathrm{pH} 7$, à temperatura ambiente, por $1 \mathrm{~h}$

\begin{tabular}{|c|c|c|c|c|}
\hline $\begin{array}{l}\text { Conc. do } \\
\text { Tampão } \\
(\mathrm{mM})\end{array}$ & $\begin{array}{l}\text { Ativ. do } \\
\text { Imobilizado } \\
\left(\mathrm{U}_{\mathrm{AO}} / \mathrm{g}\right)\end{array}$ & $\begin{array}{c}\text { Ativ. } \\
\text { Recuperada } \\
(\%)\end{array}$ & $\begin{array}{l}\text { Rendimento de } \\
\text { Imobilização (\%) }\end{array}$ & $\begin{array}{c}\text { Quant. de Proteína } \\
\text { Imobilizada (mg/g de } \\
\text { suporte) }\end{array}$ \\
\hline 50 & 0 & 0 & 19,1 & 1,1 \\
\hline 5 & 2,2 & 0 & 28,1 & 1,5 \\
\hline
\end{tabular}

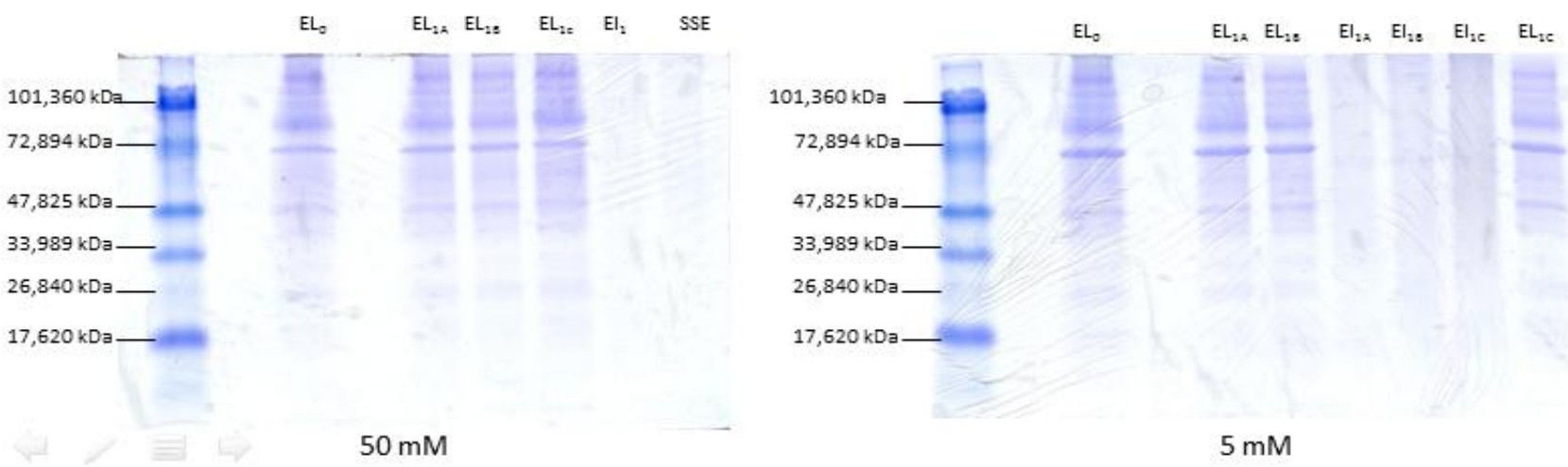

$\mathrm{EL}_{0}$ : enzima livre no tempo 0 hora; $\mathrm{EL}_{1 \mathrm{~A}}$ : enzima livre no tempo 1 hora $\mathrm{A} ; \mathrm{EL}_{1 \mathrm{~B}}$ : enzima livre no tempo 1 hora $\mathrm{B}$; $\mathrm{EL}_{1 \mathrm{C}}$ : enzima livre no tempo 1 hora $\mathrm{C}$; $\mathrm{EI}_{1 \mathrm{~A}}$ : enzima imobilizada no tempo de 1 hora $\mathrm{A}$; $\mathrm{EI}_{1 \mathrm{~B}}$ : enzima imobilizada no tempo de 1 hora $\mathrm{B}$; $\mathrm{EI}_{1 \mathrm{C}}$ : enzima imobilizada no tempo de 1 hora $\mathrm{C}$; $\mathrm{SSE}$ : suporte sem enzima.

Figura 1 - Eletroforese do estudo do efeito da força iônica no processo de imobilização de lipase de A. niger $\mathrm{C}$ em fibra de coco. 
Imobilização em octil-agarose: Avaliou-se o efeito da força iônica na imobilização de lipase de $A$. niger $\mathrm{C}$ em octil-agarose por adsorção no tempo de contato de 1 hora (Tabela 2). $\mathrm{O}$ uso da baixa força iônica também foi mais eficiente no uso do suporte homogêneo (octilagarose), onde se obteve maior atividade de enzima imobilizada, embora tenha sido observados valores de quantidade de proteína imobilizada igual para as duas condições estudadas. O perfil proteico do sobrenadante e do imobilizado também foi avaliado por eletroforese (Figura 2). Em $50 \mathrm{mM}$ não foi possível visualizar qualquer banda de proteína no suporte, já em $5 \mathrm{mM}$ percebeu-se duas bandas fracamente coradas acima e próximas a 72 $\mathrm{kDa}$.

Tabela 2 - Imobilização de lipases de A. niger $\mathrm{C}$ por adsorção em octil agarose, utilizando tampão fosfato de sódio $\mathrm{pH}$ 7, à temperatura ambiente, por $1 \mathrm{~h}$

$\begin{array}{ccccc}\begin{array}{c}\text { Conc. do } \\ \text { Tampão } \\ (\mathrm{mM})\end{array} & \begin{array}{c}\text { Ativ. do } \\ \text { Imobilizado } \\ \left(\mathrm{U}_{\mathrm{AO}} / \mathrm{g}\right)\end{array} & \begin{array}{c}\text { Ativ. } \\ \text { Recuperada }\end{array} & \begin{array}{c}\text { Rendimento de } \\ \text { Imobilização }(\%)\end{array} & \begin{array}{c}\text { Quant. de Proteína } \\ \text { Imobilizada (mg/g de } \\ \text { suporte) }\end{array} \\ 50 & 0,3 & 4,3 & 33,6 & 6,1 \\ 5 & 3,2 & 0 & 0 & 6,1\end{array}$

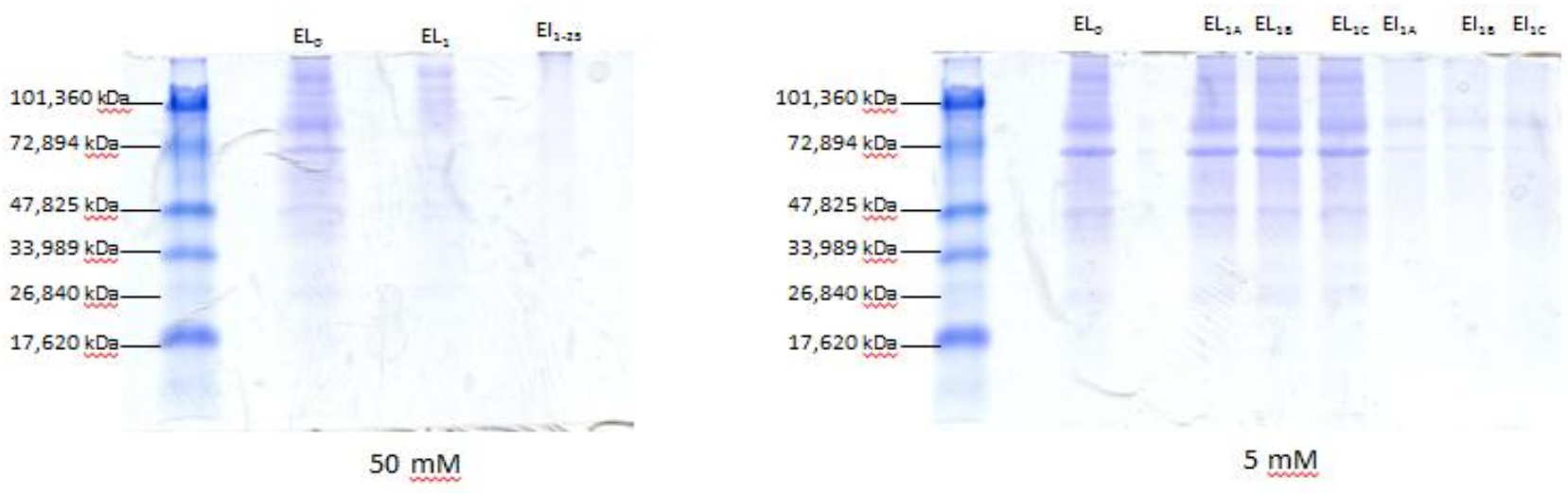

$\mathrm{EL}_{0}$ : enzima livre no tempo 0 hora; $\mathrm{EL}_{1}$ : enzima livre no tempo 1 hora; $\mathrm{EI}_{1-25}$ : enzima imobilizada no tempo de 1 hora na concentração de $25 \mathrm{mg}$; $\mathrm{EL}_{1 \mathrm{~A}}$ : enzima livre no tempo 1 hora $\mathrm{A} ; \mathrm{EL}_{1 \mathrm{~B}}$ : enzima livre no tempo 1 hora $\mathrm{B}$; $\mathrm{EL}_{1 \mathrm{C}}$ : enzima livre no tempo 1 hora $\mathrm{C} ; \mathrm{EI}_{1 \mathrm{~A}}$ : enzima imobilizada no tempo de 1 hora $\mathrm{A} ; \mathrm{EI}_{1 \mathrm{~B}}$ : enzima imobilizada no tempo de 1 hora $\mathrm{B}$; $\mathrm{EI}_{1 \mathrm{C}}$ : enzima imobilizada no tempo de 1 hora $\mathrm{C}$.

Figura 2 - Eletroforese do estudo do efeito da força iônica no processo de imobilização de lipase de A. niger $\mathrm{C}$ em octil-agarose.

O uso de baixa força iônica mostrou-se mais eficiente no processo de imobilização tanto para suporte homogêneo (octil-agarose) quanto para suporte heterogêneo (fibra de coco). Bastida et al. (1998) também obtiveram maior eficiência e rapidez na imobilização de lipase de Rhizopus niveus em octil-agarose utilizando baixa força iônica. A carga máxima de proteína imobilizada foi de $6,1 \mathrm{mg} / \mathrm{g}$ e $1,5 \mathrm{mg} / \mathrm{g}$ em octil-agarose e fibra de coco, 
respectivamente. E, quanto a atividade específica do imobilizado, esta foi de 1,5 e 0,52 $\mathrm{U}_{\mathrm{AO}} / \mathrm{mg}$ de proteína, utilizando-se fibra de coco e octil-agarose, respectivamente.

\subsection{Efeito do tempo de contato no processo de imobilização por adsorção em octil-agarose}

Considerando um maior valor de atividade hidrolítica no derivado obtido com octilagarose, este suporte foi selecionado para avaliar o efeito do tempo de contato no processo de imobilização de lipase de A. niger C. Para este estudo, optou-se por trabalhar com o método de hidrólise de p-nitro fenil butirato, por ser um método mais rápido e que utiliza menor quantidade de amostra do imobilizado.

O efeito do tempo de contato na atividade do sobrenadante e do derivado obtido pode ser visualizado na Figura 3. No tempo de 1 hora observou-se um valor máximo de atividade hidrolítica no derivado, embora o sobrenadante tenha caído apenas $50 \%$ da atividade oferecida. Maior atividade específica no derivado também foi observada após 1 hora de imobilização (Tabela 3). Fernández-Lorente et al. (2005) observaram equilíbrio de adsorção e atividade máxima em 1,5 hora de contato quando imobilizaram lipase de A. niger comercial (Fluka) em octil-agarose, $\mathrm{pH} 7$ tampão fosfato $5 \mathrm{mM}$. A pequena diferença de meia hora pode ser decorrido da diferença na quantidade de proteína oferecida por grama de suporte. Enquanto neste presente estudo foram ofertados $25,7 \mathrm{mg}$ de proteína para 1 grama de octil, nos estudos realizados por Fernández-Lorente et al. (2005) foram oferecidos $20 \mathrm{mg}$ de proteína para 1 grama de suporte.

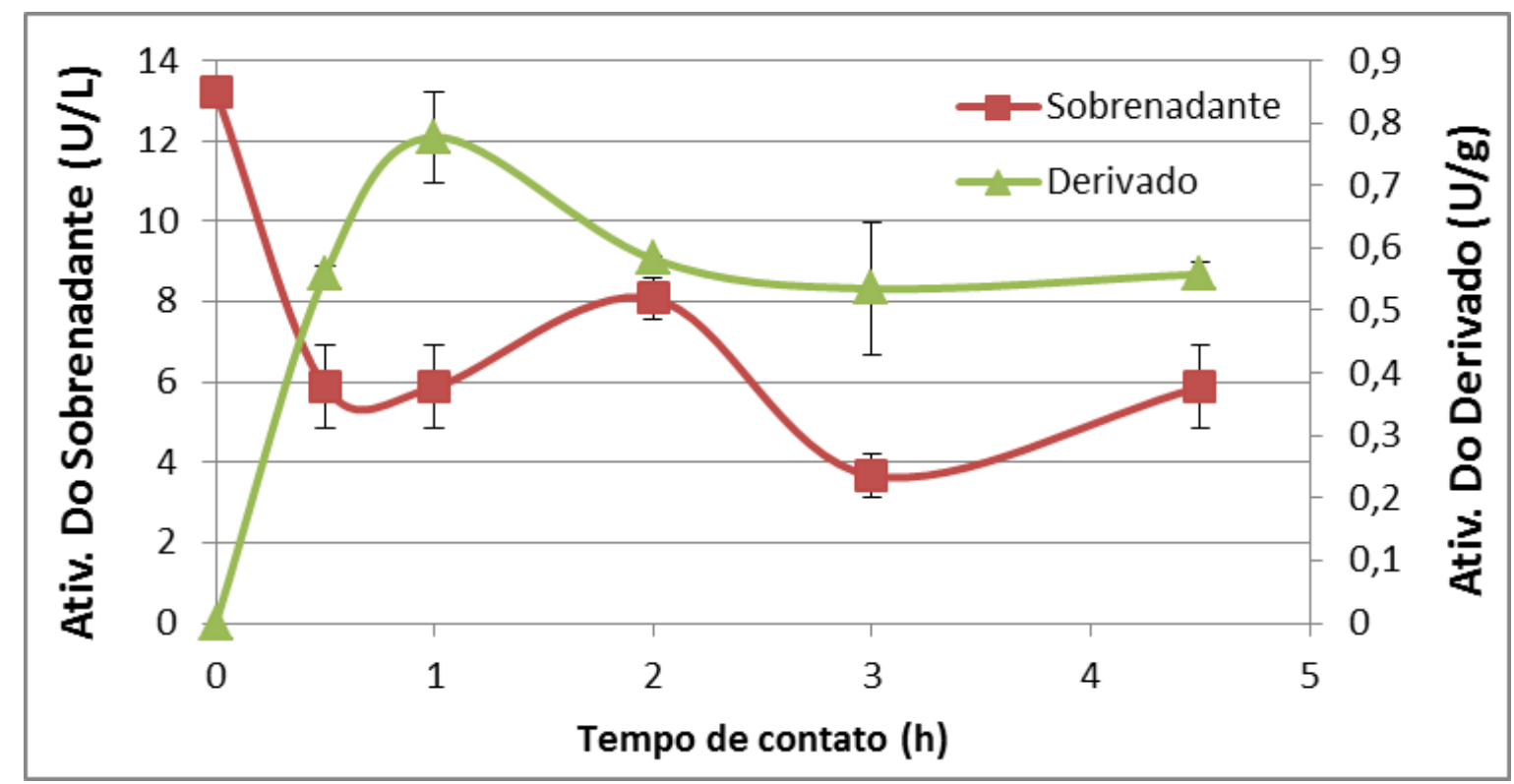

Figura 3 - Efeito do tempo de contato no processo de imobilização de lipase de A. niger C por adsorção em octil-agarose, em tampão fosfato a $5 \mathrm{mM} \mathrm{pH} 7,25^{\circ} \mathrm{C}$. 
Foi observado um aumento no teor de proteína adsorvida no suporte ao longo do processo de imobilização durante o período estudado (Tabela 3). Contudo, como houve queda na atividade do derivado após 1 hora de contato, e sabendo que o octil-agarose, em monocamada, só é capaz de adsorver $6 \mathrm{mg} / \mathrm{g}$ de proteína (dados do fabricante), pode-se supor que após esse tempo de 1 hora, ocorreu o fenômeno de adsorção em multicamada.

Tabela 3 - Parâmetros de imobilização da adsorção de lipases de A. niger C em octil-agarose, utilizando tampão fosfato de sódio $5 \mathrm{mM} \mathrm{pH} \mathrm{7,} \mathrm{à} \mathrm{temperatura} \mathrm{ambiente}$

Ativ.

$\begin{array}{cccc}\begin{array}{c}\text { Tempo } \\ (\mathrm{h})\end{array} & \begin{array}{c}\text { Específica do } \\ \text { Imobilizado } \\ \left(\mathrm{U}_{\mathrm{pNFB}} / \mathrm{mg}\right)\end{array} & \begin{array}{c}\text { Ativ. } \\ \text { Recuperada } \\ (\%)\end{array} & \begin{array}{c}\text { Rendimento de } \\ \text { Imobilização }(\%)\end{array} \\ 0,5 & 0,09 & 238 & 55 \\ 1 & 0,13 & 342 & 55 \\ 2 & 0,08 & 350 & 38 \\ 3 & 0,07 & 174 & 72 \\ 4,5 & 0,06 & 238 & 55\end{array}$

Quant. de Proteína Imobilizada (mg/g de suporte)

6,6

5,9

7,4

8,1

9,8

\section{CONCLUSÃO}

$\mathrm{O}$ uso de baixa força iônica mostrou-se mais eficiente tanto em suporte heterogêneo (fibra de coco) quanto em suporte homogêneo (octil-agarose). A carga máxima de proteína imobilizada foi de $6,1 \mathrm{mg} / \mathrm{g}$ de octil-agarose. Além disso, o octil-agarose foi o suporte que apresentou maior atividade lipolítica $(3,2 \mathrm{UAO} / \mathrm{g}) \mathrm{em} 1$ hora de contato sendo, inclusive, este o período que promoveu atividade específica máxima ( $0,13 \mathrm{UpNFB} / \mathrm{mg}$ de proteína).

\section{AGRADECIMENTOS}

Agradecemos a FAPERJ pelo auxílio financeiro e a Embrapa pela bolsa concedida.

\section{REFERÊNCIAS}

BASTIDA, A.; SABUQUILLO P.; ARMISEN, P.; FERNÁNDEZ-LAFUENTE, R.; HUGUET, J.; GUISÁN, J. M. A single step purification, immobilization, and hyperactivation of lipases via interfacial adsorption on strongly hydrophobic supports. Biotechonol. Bioeng., v. 58, p. 486-493, 1998.

BLANCO, R.M.; TERREROS, P.; PÉREZ, M. F.; OTERO, C.; GONZÁLEZ, G. Functionalization of mesoporous silica for lipase immobilization characterization of the support and the catalysts. J. Molec. Catalysis B. Enzymatic, v. 30, p. 83-93, 2004.

BRADFORD, M. M. A rapid and sensitive method for the quantification of microgram quantities of protein utilizing the principle of protein dye-binding. Anal. Biochem., v. 72, p. 248-254, 1976. 
BRÍGIDA, A. I. S.; PINHEIRO, Á. D. T.; FERREIRA, A. L. O.; GONÇALVES, L.R. B. Immobilization of Candida antarctica lipase B by adsorption to green coconut fiber. Applied Biochemistry and Biotechnology, v. 146, p. 173-187, 2008.

CONTESINI, F. J.; LOPES, D. B.; MACEDO, G. A.; NASCIMENTO, M. G.; CARVALHO, P. O. Aspergillus sp. Lipase: Potential biocatalyst for industrial use. J. Molec. Catalysis B. Enzymatic, v. 67, p. 163-171, 2010.

FERNÁNDEZ-LORENTE, G.; ORTIZ,C.; SEGURA, R. L.; FERNÁNDEZ-LAFUENTE, R.; GUISÁN, J. M.; PALOMO, J. M. Purification of different lipases from Aspergillus niger by using a highly selective adsorption on hydrophobic supports. Biotechonol. Bioeng., v. 92, p. 773-779, 2005.

GOMES, C. A. O. Produção de enzimas despolimerizantes por fermentação em meio semi sólido por Aspergillus niger 3T5B8. Rio de janeiro:UFRRJ,1995. Dissertação de Mestrado Departamento de Tecnologia de Alimentos, Instituto de Tecnologia, Universidade Federal Rural do Rio de Janeiro, 1995.

GOTTSCHALK, L.M.F.; PENHA, E.M. ; SOUZA, E. F. ; TERZI, S. C. ; VIANA, L. A. N. ; SILVA, J.L.S. . Avaliação de duas cepas de Aspergillus niger na produção de lipase por fermentação em estado sólido e submersa. In: X Seminário Brasileiro de Tecnologia Enzimática, 2012, Blumenau. CD do X Seminário Brasileiro de Tecnologia Enzimática. Blumenau: FURB, 2012.

JAEGER, K. E.; REETZ, M. T. Microbial lipases form versatile tools for biotechnology. Trends Biotechnol, v. 9, p. 396-403, 1998.

LAEMMLI, U. K. Cleavage of Structural Proteins during the Assembly of the Head of Bacteriophage T4. Nature, v. 227, p. 680-685, 1970.

MONTEIRO, V. N.; SILVA, R. DO N. Aplicações Industriais da Biotecnologia Enzimática. Revista Proc. Químicos, p. 9-23, 2009.

SHARMA, R.; CHISTI, Y.; BANERJEE, U. Production, purification, characterization and applications of lipases. Biotechnol. Adv., v. 19, p. 627-662, 2001.

VILLENEUVE, P. Customizing lipases for biocatalysis: a survey of chemical, physical and molecular biological approaches. J. Molec. Catalysis B. Enzymatic, v. 9, p. 113-148, 2000. 